\title{
Size-Dependent Labor Regulations and Structural Transformation in India
}

\author{
Wenbiao Cai and Manish Pandey \\ Department of Economics Working Paper Number: 2012-03
}

THE UNIVERSITY OF WINNIPEG

Department of Economics

515 Portage Avenue

Winnipeg, R3B 2E9

Canada

This working paper is available for download from:

http://ideas.repec.org/s/win/winwop.html 


\title{
Size-Dependent Labor Regulations and Structural Transformation in India
}

\author{
Wenbiao Cai* Manish Pandey ${ }^{\dagger}$
}

October 29, 2012

\begin{abstract}
Labor regulations in India increase the cost of hiring labor for larger establishments and have been cited as an important reason for the lack of mid-sized establishments in the manufacturing sector. Using data for India, we calibrate a two-sector model in which agents differ in their managerial ability in manufacturing. In the presence of size-dependent labor regulations, the model generates the observed employment distribution across manufacturing establishments in India. In a counterfactual exercise, removing the regulations increases aggregate output per worker by $2.3 \%$ and also increases labor productivity in agriculture relative to manufacturing by $4 \%$. We find that labor regulations in manufacturing have a detrimental effect on the productivity of the agricultural sector and hence impede the process of structural transformation.
\end{abstract}

Journal of Economic Literature Classification Numbers: K31; O11; O40

keywords: Size-dependent Policy; Structural Transformation; India

* Corresponding Author: Department of Economics, University of Winnipeg. 515 Portage Avenue, Winnipeg, Manitoba, R3B2E9, Canada. Phone: 1-204-258-2984; fax: 1-204-772-4183; email: we.cai@uwinnipeg.ca.

${ }^{\dagger}$ Department of Economics, University of Winnipeg. 515 Portage Avenue, Winnipeg, Manitoba, R3B2E9, Canada. Phone: 1-204-786-9289; fax: 1-204-772-4183; email: m.pandey@uwinnipeg.ca. 


\section{Introduction}

Government policy distortions that depend on establishment size reduce aggregate output and productivity (Guner, Ventura, and Xu, 2008; Restuccia and Rogerson, 2008). In India, manufacturing establishments with more than a certain number of employees (registered establishments) face labor regulations, while smaller (unregistered) establishments do not (Besley and Burgess, 2004). These size-dependent policies make it costlier to operate larger establishments, and have been cited as an important reason for the lack of mid-sized establishments in the manufacturing sector in India, also termed as the "missing middle" (Krueger, 2007). ${ }^{1}$

We use a simple growth model to quantitatively evaluate the effects of size-dependent labor regulations in India. Our contribution is two-fold. First, we show quantitatively that size-dependent regulations can generate the observed "missing middle" in Indian manufacturing. Second, we examine the role of such distortions in the manufacturing sector for understanding structural transformation in developing countries like India.

We extend the Lucas (1978) span-of-control framework to include two sectors: agriculture and manufacturing. Agents in the model differ in managerial ability in manufacturing and decide whether to work or operate an establishment. If they choose to be managers, they decide on how much capital and labor to employ for production. Since managerial services are an input in production, differences in ability lead to differences in establishment sizes. Size-dependent labor regulations of the kind observed in India are modeled as a labor tax that increases the cost of labor for establishments larger than a certain size.

We calibrate the model using data for India and determine the labor tax required for matching key observations in the data. The calibrated model successfully generates the "missing middle" observed in Indian manufacturing. We then undertake a counterfactual exercise in which the size-dependent labor regulations are removed. We find that removing the regulations increases aggregate output per worker by $2.3 \%$ and reduces the share of labor in agriculture by $2 \%$. Hence, such labor regulations in manufacturing impede structural transformation in India. Furthermore, labor productivity in agriculture relative to manufacturing increases by $4 \%$ following the removal of the regulations. This suggests that size-dependent

\footnotetext{
${ }^{1}$ Krueger (2007) states that the "failure of [Indian] manufacturing output and employment to grow more rapidly can be attributed to (1) regulations governing enterprises in the private sector and (2) regulations covering conditions of employment of labor." We quantify the gains in employment and output for the manufacturing sector from removing size-dependent labor regulations in India.
} 
labor regulations in manufacturing are important for understanding systematically lower labor productivity in agriculture relative to manufacturing in developing countries documented by Gollin, Parente, and Rogerson (2004). ${ }^{2}$

Once the regulations are removed, the employment distribution across manufacturing establishments changes dramatically. The share of employment in mid-sized establishments, for example, increases from $11 \%$ in the distorted economy to $37 \%$ in the undistorted economy. Moreover, after removing the regulations, the employment distribution across manufacturing establishments in India is remarkably similar to that of Korea, an economy which did not have such regulations.

The rest of the paper is organized as follows. Section 2 describes the model. Section 3 explains the calibration strategy and provides the main quantitative results. Section 4 concludes.

\section{Model}

The economy is populated with $N$ individuals and endowed with initial physical capital $K_{0}$ and a fixed stock of land $Z$. Individuals differ in their managerial ability, denoted by $x$. These managerial abilities are distributed with support $(0, \infty)$ and cdf $G(x)$. We assume a stand-in household that owns all capital and land, and makes all economic decisions.

Technology Two goods are produced in this economy. The agriculture good $\left(Y_{a}\right)$ is produced using capital $\left(K_{a}\right)$, labor $\left(N_{a}\right)$ and land $(Z)$ according to

$$
Y_{a}=A \cdot K_{a}^{\alpha} Z^{\psi} N_{a}^{1-\alpha-\psi},
$$

where $A$ is total factor productivity. The technology for producing manufacturing good, on the other hand, requires capital, labor and managerial ability:

$$
y_{m}(x)=A \cdot x^{1-\gamma}\left(k^{\theta} n^{1-\theta}\right)^{\gamma},
$$

where $\gamma$ is the span of control parameter. Agriculture output can only be consumed, while manufacturing output can be consumed or converted into physical capital.

\footnotetext{
${ }^{2}$ To the best of our knowledge, this mechanism has not been examined in the literature on explaining differences in relative productivity of agriculture to manufacturing across countries.
} 
As in Lucas (1978), individuals sort themselves between workers and managers. The former earns a market wage rate $(w)$, regardless of managerial ability. The latter produces manufacturing output and retains residual profit after capital rental $(r)$ and wage payments, i.e., managers solve the following problem:

$$
\max _{\{k, n\}} A \cdot x^{1-\gamma}\left(k^{\theta} n^{1-\theta}\right)^{\gamma}-r k-w n
$$

We denote the corresponding factor demand functions by $k(x)$ and $n(x)$, and the residual profit function by $\pi(x)$.

Size-dependent Labor Regulations We consider a form of labor regulations where the government levis a labor tax, $\tau$, on establishments with employment above $\bar{n} .{ }^{3}$ Specifically, the unit cost of labor for employment size below $\bar{n}$ is $w$, and for size $\bar{n}$ and above is $w(1+\tau)$. These tax proceeds are reimbursed back to the household in a lump-sum fashion. This policy implies three types of managers in equilibrium: 1) unconstrained ones whose optimal size is below $\bar{n}$; 2) constrained ones who operate with $\bar{n}$ employees; 3) high ability managers operating large establishments. Correspondingly, there are three thresholds of managerial ability, $x_{1}<x_{2}<x_{3}$. Managers with ability $x \in\left[x_{1}, x_{2}\right]$ operate unconstrained plants. Those with ability $x \in\left(x_{2}, x_{3}\right]$ operate plants with size $\bar{n}$. Finally those with ability $x>x_{3}$ operate large plants. The first two thresholds are determined as

$$
\begin{aligned}
& w=\pi\left(x_{1} ; w, r\right), \\
& \bar{n}=n\left(x_{2} ; w, r\right) .
\end{aligned}
$$

Equation (3) is the indifference condition for the marginal manager between operating an establishment and working. Equation (4) states that the marginal constrained manager has an optimal size that is equal to $\bar{n}$. To determine $x_{3}$, first consider the constrained mangers operating with $n=\bar{n}$ who solve the following problem:

$$
\max _{k} A \cdot x^{1-\gamma}\left(k^{\theta} \bar{n}^{1-\theta}\right)^{\gamma}-r k
$$

Denote the corresponding profit function by $\tilde{\pi}(x ; \bar{n}, r)$. The manager with ability $x_{3}$ is indif-

\footnotetext{
${ }^{3}$ For modeling the labor regulations in India, Besley and Burgess (2004) use a similar form for it. Guner, Ventura, and Xu (2008) also use a similar formulation for their model for labor regulations in Italy.
} 
ferent between operating a constrained plant and paying the labor tax, i.e.,

$$
\pi\left(x_{3} ; w(1+\tau), r\right)=\tilde{\pi}\left(x_{3} ; \bar{n}, r\right)
$$

Preferences We assume household preferences are represented by the following instantaneous utility function:

$$
U\left(c_{a}, c_{m}\right)=\eta \log \left(c_{a}-\bar{a}\right)+(1-\eta) \log \left(c_{m}\right)
$$

where $c_{a}$ and $c_{m}$ denote agriculture and manufacturing consumption, respectively. The parameter $\eta$ is the expenditure share for the agriculture good, and $\bar{a}$ has the usual interpretation of subsistence. ${ }^{4}$

Household Problem The problem of the household is to divide family members between workers and managers, and split household income between consumption and investment. Household income consists of labor income, capital and land rental income, residual profits of managers, and government transfers (TR). Formally, the stand-in household's problem is

$$
\begin{aligned}
\max _{\left\{x_{1}, x_{2}, x_{3}, c_{a t}, c_{m t}, K_{t+1}\right\}} & \sum_{t=0}^{\infty} \beta^{t} U\left(c_{a t}, c_{m t}\right) \\
\text { s.t. : } & p_{t} c_{a t}+c_{m t}+K_{t+1}=Y_{t}+(1-\delta) K_{t},
\end{aligned}
$$

where $Y_{t}=w_{t} \cdot G\left(x_{1}\right)+\int_{x_{1}}^{x_{2}} \pi\left(x ; w_{t}, r_{t}\right) d G(x)+\int_{x_{2}}^{x_{3}} \tilde{\pi}\left(x ; \bar{n}, r_{t}\right) d G(x)+\int_{x_{3}}^{\infty} \pi\left(x ; w_{t}(1+\tau), r_{t}\right) d G(x)+$ $r_{t} K_{t}+q_{t} Z+T R_{t}$. The rate of capital depreciation is denoted by $\delta ; p_{t}$ is the price of agriculture output and $q_{t}$ is the rental price of land, both expressed in terms of manufacturing output. Equilibrium We define a stationary competitive equilibrium as a collection of prices $(w, r, p, q)$, managerial skill cut-offs $\left(x_{1}^{*}, x_{2}^{*}, x_{3}^{*}\right)$, and allocations $\left(c_{a}^{*}, c_{m}^{*}, K_{a}^{*}, N_{a}^{*}, K^{*}, T R^{*}\right)$ such that(i) given prices, managers maximize profit and household maximizes utility; (ii) labor,

\footnotetext{
${ }^{4}$ The subsistence parameter is standard in the structural transformation literature. See for example Kongsamut, Rebelo, and Xie (2001) and Gollin, Parente, and Rogerson (2007).
} 
capital, and goods markets clear, i.e.,

$$
\begin{aligned}
G\left(x_{1}^{*}\right) & =N_{a}^{*}+\int_{x_{1}^{*}}^{x_{2}^{*}} n(x ; w, r) d G(x)+\left[G\left(x_{3}^{*}\right)-G\left(x_{2}^{*}\right)\right] \bar{n}+\int_{x_{3}^{*}}^{\infty} n(x ; w(1+\tau), r) d G(x), \\
K^{*} & =K_{a}^{*}+\int_{x_{1}^{*}}^{x_{2}^{*}} k(x ; w, r) d G(x)+\int_{x_{2}^{*}}^{x_{3}^{*}} k(x ; \bar{n}, r) d G(x)+\int_{x_{3}^{*}}^{\infty} k(x ; w(1+\tau), r) d G(x), \\
c_{a}^{*} & =A K_{a}^{* \alpha} Z^{\psi} N_{a}^{* 1-\alpha-\psi}, \\
c_{m}^{*}+\delta K^{*} & =\int_{x_{1}^{*}}^{x_{2}^{*}} y_{m}(x ; w, r) d G(x)+\int_{x_{2}^{*}}^{x_{3}^{*}} y_{m}(x ; \bar{n}, r) d G(x)+\int_{x_{3}^{*}}^{\infty} y_{m}(x ; w(1+\tau), r) d G(x) ;
\end{aligned}
$$

(iii) government budget balances:

$$
T R^{*}=\tau \cdot w \cdot \int_{x_{3}^{*}}^{\infty} n(x ; w(1+\tau), r) d G(x) .
$$

\section{Quantitative Analysis}

We calibrate the steady state version of the model to Indian data and determine the labor tax required for matching key observations in the data. Then we consider a counterfactual exercise in which the size-dependent regulations are removed and report the quantitative implications.

\subsection{Calibration}

The size of the labor force is normalized to be 1 , so is total factor productivity. We set $Z=0.29$, which is the land-employment ratio for India for 1994 from World Development Indicator. For the span-of-control parameter, we follow Guner, Ventura, and Xu (2008) and set $\gamma=0.8$. For factor shares, we use estimates from Valentinyi and Herrendorf (2008) and set $\alpha=0.3, \psi=0.11$ and $\theta=0.41$. For the rate of capital depreciation, we choose a standard value $\delta=0.06$. Following Restuccia, Yang, and Zhu (2008), we set $\eta=0.005$, which implies a long run expenditure share for the agriculture good of 0.5 percent. In India, manufacturing plants with 10 employees or more must register with the government. Correspondingly, we set $\bar{n}=9 .^{5}$

\footnotetext{
${ }^{5}$ More precisely, according to the Factories Act of 1948, manufacturing firms with ten or more employees with power, or twenty without power must register with the government. See Besley and Burgess (2004).
} 
We assume that the managerial abilities distribution $(G(x))$ is log-normal with mean $\mu$ and variance $\sigma^{2}$. The distribution parameters $(\mu$ and $\sigma)$, the subsistence parameter, $\bar{a}$, the discount factor, $\beta$, and the labor tax rate, $\tau$, are chosen simultaneously to match the following observations in India: i) capital-output ratio; ii) the share of employment in small establishments ( $\leq 9$ employees); iii) the share of employment in large establishments $(500+$ employees); iv) the percentage of small establishments in total number of establishments; v) the share of labor in agriculture. ${ }^{6,7}$ These parameter values are summarized in Table 1 . The model fits calibration targets almost perfectly.

Table 1: Parameter Value, Targets, and Model Fits

\begin{tabular}{l|ccccc}
\hline \hline Parameter & $\mu$ & $\sigma$ & $\bar{a}$ & $\beta$ & $\tau$ \\
\hline Value & -7.78 & 2.95 & 0.499 & 0.879 & 0.089 \\
\hline \hline
\end{tabular}

\begin{tabular}{lcc}
\hline \hline Target & Data & Model \\
\hline Capital to Output Ratio & 1.58 & 1.58 \\
Share of Employment in Small Establishments $(\leq 9)$ & 0.415 & 0.414 \\
Share of Employment in Large Establishments $(\geq 500)$ & 0.231 & 0.231 \\
Percentage of Small Establishments $(\leq 9)$ & 95.5 & 96.0 \\
Share of Labor in Agriculture & 0.62 & 0.62 \\
\hline \hline
\end{tabular}

Three remarks are in order. First, as Figure 1 illustrates, even though in our calibration we target only the employment shares at the two ends of the distribution, the model generates a U-shaped employment distribution across manufacturing establishments, i.e., the "missing middle". Second, although not targeted, the model replicates the percentage of medium (10-99) and large establishments in total establishments in the data. ${ }^{8}$ Third, the calibrated implicit labor tax is relatively modest (8.9\%). In fact, this is roughly the midpoint of the implicit tax rates considered in Guner, Ventura, and Xu (2008).

\footnotetext{
${ }^{6}$ The capital-output ratio is computed using capital stock and output data from Caselli (2005) for year 1996.

${ }^{7}$ Data on employment distribution are from Mazumdar and Sarkar (2008), while data on percentage of small establishments are from Bhattacharya (2009). Their data covers both registered and non-registered manufacturing establishments in India from 1989-1990.

${ }^{8}$ The percentage of medium (large) establishments in total establishments is $2.3 \%$ (0.9\%) in the data, and $2 \%(0.2 \%)$ from the model. Data is from Bhattacharya (2009).
} 
Figure 1: Employment Share by Establishment Size in India: Model and Data

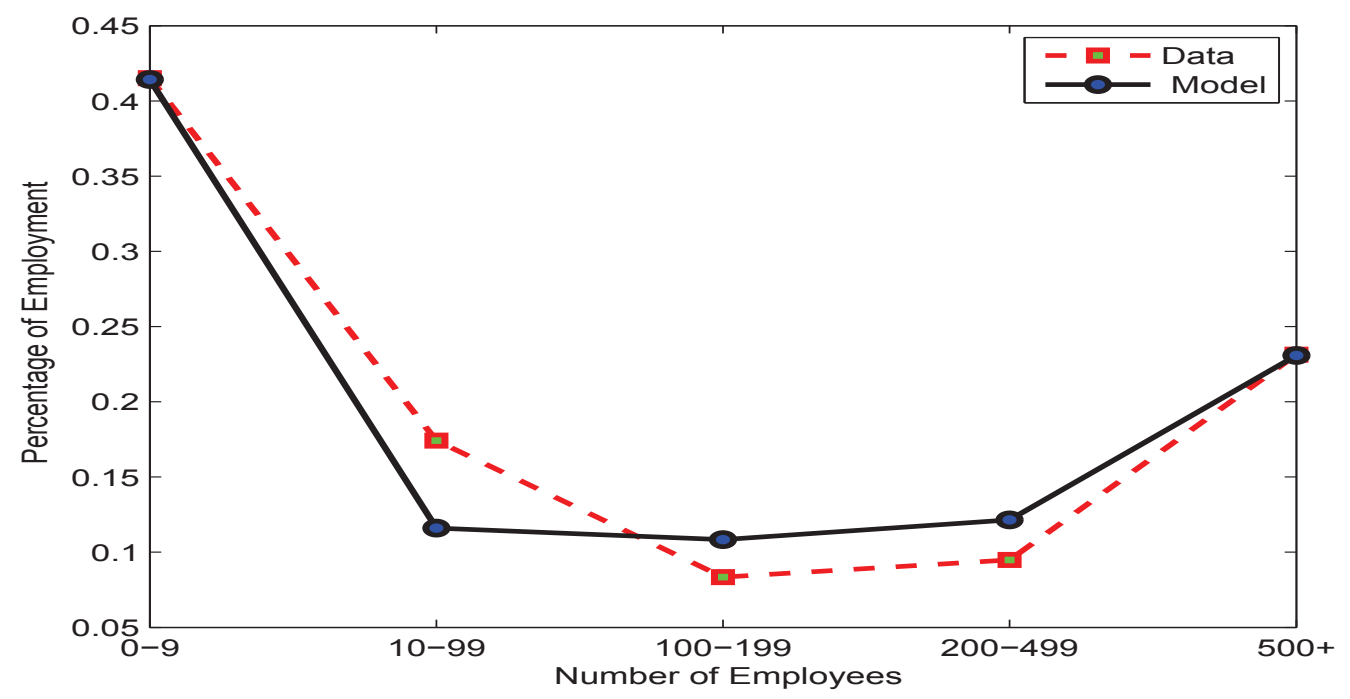

\subsection{Counterfactual}

We use the calibrated model to perform a counterfactual exercise, in which the labor regulations are removed. We report changes in aggregate output, sectoral labor allocation, and the distribution of employment across establishments associated with the removal of the regulations. These results are summarized in Table 2.

Removing the size-dependent regulations increases aggregate output per worker by $2.3 \%$. We find that the increase in real output per worker is in fact higher in agriculture $(2.8 \%)$ than in manufacturing $(0.7 \%)$. The gain in labor productivity in agriculture is accounted for mostly by increase in capital allocation for the sector. In manufacturing, total factor productivity increases by $0.4 \%$, which arises from the reallocation of capital and labor from smaller, less productive establishments to larger, more productive ones. ${ }^{9}$ There are two reasons for this. First, previously constrained managers now operate at their optimal (and larger) scale in the undistorted economy. ${ }^{10}$ Second, increased wage forces the exit of small establishments. The measure of managers decreases from $2.65 \%$ to $2.12 \%$, which leads to an increase in average managerial ability by $21 \%$.

Across sectors, the removal of size-dependent regulations induces the migration of labor

\footnotetext{
${ }^{9}$ We calculate TFP in manufacturing as $Y_{m} /\left(K_{m}^{\theta}\left[G\left(x_{1}\right)-N_{a}\right]^{1-\theta}\right)^{\gamma}$.

${ }^{10}$ In the distorted economy, $27 \%$ of managers are constrained.
} 
Table 2: Effects of Size-dependent Regulations: The Case of India

\begin{tabular}{lcc}
\hline \hline & Distorted & Undistorted \\
\hline I. Aggregate & & \\
\hline & & \\
Real GDP per Worker & 0.475 & 0.486 \\
Capital Stock & 0.75 & 0.792 \\
& & \\
II. Sectoral & 62 & \\
\hline & & \\
Share of Labor in Agriculture (\%) & 2.65 & 2.12 \\
Share of Managers (\%) & 1.05 & 1.27 \\
Average Managerial Ability & 0.72 & 0.75 \\
Relative Productivity (Agr./Man.) & 0.48 & 0.51 \\
Capital to Output Ratio (Agr./Man.) & & \\
& & \\
III. Employment Distribution by Size & & \\
\hline & 13 & \\
Mean Establishment Size & & \\
$\quad$ Share of Employments (\%) & 41.5 & 18.8 \\
$<10$ employees & 11.2 & 36.8 \\
10 - 99 employees & 23.1 & 21.7 \\
\hline > 500 employees
\end{tabular}

from less productive agriculture to more productive manufacturing. Relative to the distorted economy, the undistorted economy has $2 \%$ less labor employed in agriculture. This is quite significant given that structural transformation in India has been rather slow - the share of labor in agriculture has decreased by only $6 \%$ from 1963 to $1993 .^{11}$

We also find that removing the regulations increases labor productivity in agriculture relative to manufacturing by $4 \%$. A stylized fact documented by Gollin, Parente, and Rogerson (2004) is that labor productivity in agriculture relative to manufacturing is systematically lower in developing countries like India. Our findings provide an novel mechanism, which operates through size-dependent labor regulations in manufacturing, for understanding the systematic differences in relative productivity across countries. ${ }^{12}$ In our model, there are two

\footnotetext{
${ }^{11}$ Long run series of employment by sector is from Timmer and de Vries (2009).

${ }^{12}$ Gollin, Parente, and Rogerson (2004) and Restuccia, Yang, and Zhu (2008) discuss other mechanisms for explaining the systematic differences in relative productivity of agriculture across countries.
} 
Figure 2: Employment Share by Establishment Size: Korea and India (undistorted)

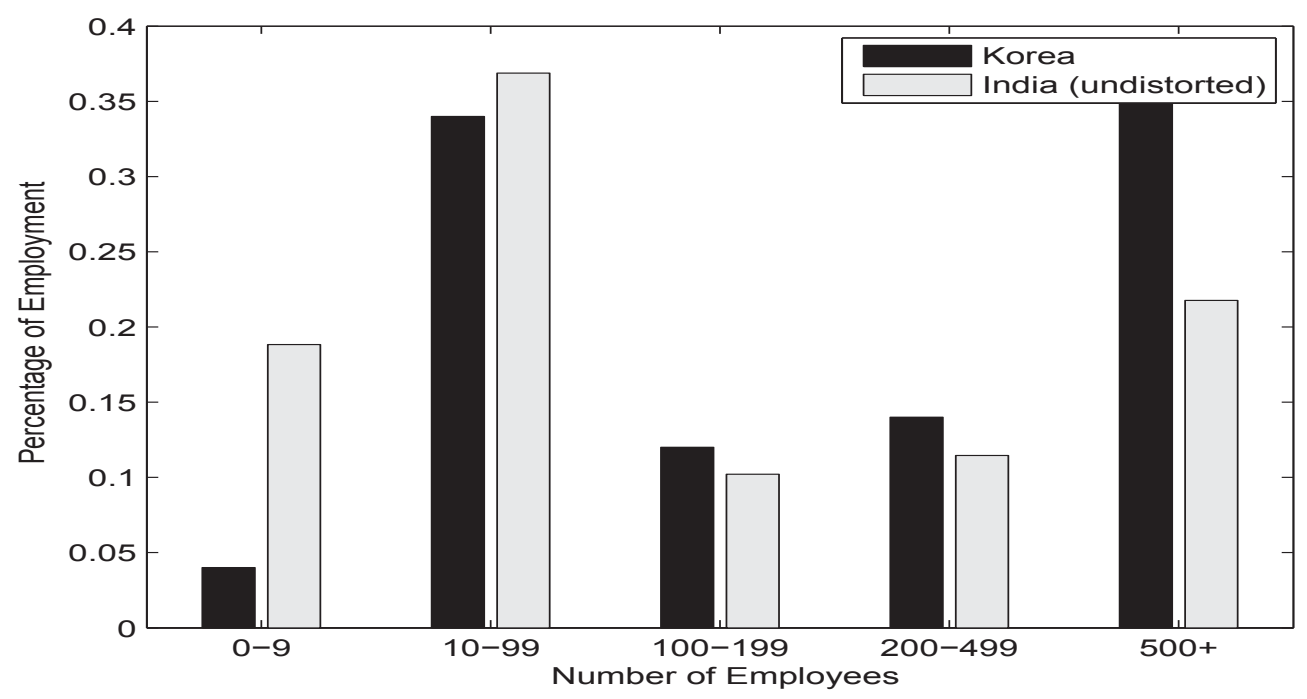

reason why size-dependent labor regulations reduce labor productivity in agriculture relative to manufacturing. First, the labor tax directly increases wage rate in large establishments, and hence, results in a higher marginal product of labor in manufacturing than in agriculture. Second, constrained establishments operate with a higher capital-labor ratio, relative to unconstrained ones. This follows from the fact that constrained managers can freely adjust capital input with ability, but not labor. ${ }^{13}$

Removing the labor regulations increases the average establishment size in manufacturing, from 13 to 18 employees. Moreover, there is massive reallocation of labor across establishments. In particular, the share of employment in small establishments drops substantially, from $42 \%$ to $19 \%$. This lost employment is mostly absorbed by medium size establishments (10 - 99 employees), whose share of employment rises from $11 \%$ to $37 \%$. As a comparison, Figure 2 plots the employment distribution across manufacturing establishments for India without the labor regulations, along with the distribution observed in the data for Korea, a country in which labor regulations are much less stringent. The clear message from the figure is that once the regulations are removed, the employment distribution in mid-sized establishments in India looks remarkably similar to that in Korea. ${ }^{14}$

\footnotetext{
${ }^{13}$ The capital-output ratio in agriculture relative to manufacturing increases from 0.48 to 0.51 once the regulations are removed (Table 2 ).

${ }^{14}$ Korean data (for year 1986) is from Mazumdar and Sarkar (2008), Figure 3.
} 


\section{Conclusion}

Labor regulations increase the cost of hiring labor for larger establishments and have been cited as the reason for the "missing middle" in Indian manufacturing. Using data for India, we calibrate a two-sector model in which agents differ in their managerial abilities and successfully generate this "missing middle". We use the model to undertake a counterfactual exercise where we remove the labor regulations and evaluate the changes. We find that removing the regulations leads to reallocation of labor and capital and results in a $2.3 \%$ increase in GDP per worker. Moreover, the reallocation also results in an increase in labor productivity of agriculture relative to manufacturing and a decrease in employment share of agriculture. While most studies on the role of size-dependent policies have examined their implications for a particular sector, we argue that the existence of such policies in the manufacturing sector can have a detrimental effect on the productivity of the agricultural sector and hence impede the process of structural transformation. Our findings highlight the need for further studies on the role of size-dependent regulations in explaining the documented lower labor productivity in agriculture relative to manufacturing in developing countries.

\section{References}

Besley, T., and R. Burgess (2004): "Can Labor Regulation Hinder Economic Performance? Evidence from India," The Quarterly Journal of Economics, 119(1), 91-134.

Bhattacharya, D. (2009): "Aggregate Barriers, Eestablishment Size and Economic Development," mimeo.

Caselli, F. (2005): "Accounting For Cross Country Income Differences," in Handbook of Economic Growth, ed. by P. Aghion, and S. D. Durlauf, pp. 679-741. ELSEVIER.

Gollin, D., S. L. Parente, and R. Rogerson (2004): "Farm work, Home Work and International Productivity Differences," Review of Ecconomic Dynamics, 7(4), 827-850.

- (2007): "The Food Problem and the Evolution of International Income Levels," Journal of Monetary Economics, 54(4), 1230-1255.

Guner, N., G. Ventura, and Y. Xu (2008): "Macroeconomic Implications of Size-Dependent Policies," Review of Economic Dynamics, 11(4), 721-744.

Kongsamut, P., S. Rebelo, and D. Xie (2001): "Beyond Balanced Growth," Review of Economic Studies, 68, 869-882. 
Krueger, A. O. (2007): "Agriculture and Aggregate Productivity: A Quantitative Crosscountry Analysis," SCID Working Paper No. 343.

Lucas, R. E. (1978): "On the Size Distribution of Business Firms," Bell Journal of Economics, $9(2), 508-523$.

Mazumdar, D., and S. Sarkar (2008): "The Employment Problem in India and the Phenomenon of the Missing Middle," paper presented at the Canadian Economics Association Meetings in Vancouver.

Restuccia, D., and R. Rogerson (2008): "Policy Distortions and Aggregate Productivity with Heterogeneous Plants," Review of Economic Dynamics, 11(4), 702-720.

Restuccia, D., D. T. Yang, and X. Zhu (2008): "Agriculture and Aggregate Productivity: A Quantitative Cross-country Analysis," Journal of Moneytary Economics, 55(2), 234-250.

Timmer, M. P., and G. J. de Vries (2009): "Structural Change and Growth Accelerations in Asia and Latin America: A New Sectoral Data Set," Cliometrica, 3(2), 165-190.

Valentinyi, A., and B. Herrendorf (2008): "Measuring Factor Income Shares at the Sector Level," Review of Economic Dynamics, 11(4), 820-835. 